\title{
Quantifying the effects of climate and surface change on glacier mass balance
}

\author{
D. H. Elsberg, ${ }^{1}$ W. D. Harrison, ${ }^{1}$ K. A. Eahelmeyer, ${ }^{1}$ R. M. Krimmel ${ }^{2}$ \\ ${ }^{1}$ Geophysical Institute, University of Alaska Fairbanks, Fairbanks, Alaska 99775-7320, U.S.A. \\ ${ }^{2}$ U.S. Geological Survey, Tacoma, Washington 98416, U.S.A.
}

\begin{abstract}
When a mass balance is computed using an outdated map, that computation does not reveal the actual mass change. But older maps often must be used for practical reasons. We present a method by which, with a few additional measurements each year, a mass balance computed with an outdated map can be transformed into an actual mass change. This is done by taking into account the influence of changes in areal extent and changes in the surface elevation of the glacier since the map was made. This method is applied to South Cascade Glacier, Washington, U.S.A., as an example. The computed cumulative mass balance from 1970 to 1997 would have been $16 \%$ too negative if the 1970 map had not been updated. While the actual volume change of a glacier is relevant to hydrological studies, the change that would have occurred on a constant (or static) surface is more relevant to certain glacier dynamics problems and most climate problems. We term this the reference-surface balance and propose that such a balance, which deliberately omits the influence of changes in area and surface elevation, is better correlated to climatic variations than the conventional one, which incorporates those influences.
\end{abstract}

\section{INTRODUCTION}

The resources available to mass-balance programs throughout the world are nearly as distinct and varied as the glaciers themselves, but some minimum level of data collection is necessary for mass-balance calculations. For example, to compute a glacier-wide annual balance by some version of the "traditional" glaciologic method (Østrem and Brugman, 1991), specific balances, measured at several points, are integrated over a map of the glacier. Unless that map is concurrent with the specific balance measurements the results will not reflect the actual glacier change. Unfortunately, few mass-balance programs have the resources to map the glacier each year. Thus the integration is likely to be performed over an outdated map, which in the extreme case may date from the beginning of the program. The resulting errors in glacier-wide annual balances may seem small, but they are systematic, and can give rise to substantial errors in a cumulative balance series constructed by summation. As we will show in an example, on South Cascade Glacier, Washington, U.S.A., this error in the cumulative balance series is $16 \%$ of the magnitude of the cumulative mass balance over a period of 27 years and will likely continue to grow with time. One of the main purposes of this paper is to show how these errors can be removed, at least approximately, without the benefit of reliable annual maps.

When computed correctly, the "conventional" mass balance is the actual ice- or water-equivalent change of a glacier over some specified time interval, not necessarily 1 year. It is useful to let the time interval approach zero, and to speak of a balance rate as a continuous function of time. Then the conventional balance rate depends upon both climate and the configuration of the surface, each of which is a continuous function of time. We introduce a dif- ferent balance rate by defining the "reference surface" as the configuration of the surface as it was at some conveniently chosen time, perhaps at the beginning of a balance program or at the date of the best map. The climate still varies with time, but the reference surface is held constant. The balance rate as it would have been on this reference surface is the "reference-surface" balance rate. This is best illustrated by the extreme example given above, in which only one map is available. If each year one assumes that specific balance is a function of elevation only, and integrates it over this original map, one is computing the reference-surface glacier-wide annual balance series for the surface defined by that map.

Because the reference-surface annual balance is calculated without an updated map, the most difficult step in determining conventional annual balance in the absence of annual maps is to find the transformation between the two balances. This is the topic of the next section. In later sections we summarize the transformation, apply it in exact form to South Cascade Glacier in order to suggest approximations necessary in typical applications, and review the data needed for the transformation. In the context of this paper, the word "transformation" refers to the change from a referencesurface balance to a conventional balance.

An important point here is that both conventional and reference-surface balances have appropriate applications, and both should be computed and reported. In hydrological studies, including water storage and sea-level change, the conventional mass balance is relevant because it is a measure of the actual change in volume of a glacier. Because a conventional mass balance incorporates both climatic forcing and surface change, the results are not simply correlated to variations in the climate. The reference-surface mass balance removes the surface change effects by holding the glacier surface constant through time, and thus is the 
Table 1. Key variables used throughout the paper, along with definitions and typical units (all balances are given in iceequivalent units)

\begin{tabular}{|c|c|c|}
\hline Variable & Definition & Unit \\
\hline $\mathrm{X}^{\prime}$ & Primed quantities are on the reference surface & \\
\hline$\dot{\mathrm{X}}$ & Dotted quantities are rates & $a^{-1}$ \\
\hline $\mathrm{X}^{(\text {cumul })}$ & $\begin{array}{l}\text { (cumul) superscript implies accumulation over many } \\
\text { years }\end{array}$ & \\
\hline$\dot{b}$ & Conventional specific balance rate & $\mathrm{ma}^{-1}$ \\
\hline$b$ & Conventional specific balance (over some time interval) & $\mathrm{m}$ \\
\hline$\dot{b}^{\prime}$ & Reference-surface specific balance rate & $\mathrm{ma}^{-1}$ \\
\hline$b^{\prime}$ & Reference-surface specific balance & $\mathrm{m}$ \\
\hline$B$ & Glacier-wide balance & $\mathrm{m}^{3}$ \\
\hline$A$ & Map area & $\mathrm{m}^{2}$ \\
\hline$\dot{G}$ & Specific balance-rate gradient, $\partial \dot{b} / \partial z$ & $\mathrm{~m} \mathrm{~m}^{-1} \mathrm{a}^{-1}$ \\
\hline$G$ & Specific balance gradient, $\partial b / \partial z$ & $\mathrm{~m} \mathrm{~m}^{-1}$ \\
\hline$Z$ & Elevation at a point on the surface & $\mathrm{m}$ \\
\hline$x, y, z$ & Independent variables of position & $\mathrm{m}$ \\
\hline $\mathcal{Z}$ & Altitude range of glacier in limits of integration & $\mathrm{m}$ \\
\hline $\mathcal{A}$ & Area distribution function, $\mathcal{A}(z)$ & $\mathrm{m}^{2} \mathrm{~m}^{-1}$ \\
\hline$\Delta A$ & $\begin{array}{l}\text { Difference in actual map area from the reference } \\
\text { surface area }\end{array}$ & $\mathrm{m}^{2}$ \\
\hline$\Delta V$ & $\begin{array}{l}\text { Difference in actual volume from the reference glacier } \\
\text { volume }\end{array}$ & $\mathrm{m}^{3}$ \\
\hline$\dot{G}_{\mathrm{e}}$ & $\begin{array}{l}\text { Weighted average of } \dot{G} \text {, with weighting given by } \\
\text { amount of elevation change from the reference glacier }\end{array}$ & $\mathrm{m} \mathrm{m}^{-1} \mathrm{a}^{-1}$ \\
\hline$b_{\mathrm{r}} ; b_{\mathrm{e}}$ & $\begin{array}{l}\text { Specific balance on the bedrock surface; average of } b_{\mathrm{r}} \\
\text { over entire } \Delta A \text { region }\end{array}$ & $\mathrm{m}$ \\
\hline$b_{\mathrm{t}^{\prime}} ; b_{\mathrm{t}}$ & $\begin{array}{l}\text { Specific balance at the reference terminus elevation; } \\
\text { actual terminus elevation }\end{array}$ & $\mathrm{m}$ \\
\hline
\end{tabular}

climatically relevant mass balance. Conveying this idea is the other main purpose of this paper.

\section{THE RELATIONSHIP BETWEEN CONVENTIONAL AND REFERENGE-SURFACE BALANGES}

\section{Mass-balance notation}

Our notation generally follows standard conventions: $\dot{b}$ is used for the balance rate, and $b$ for the balance during a specified finite time interval. We call these "specific" quantities because they are defined at a point. Note that they are measured in the vertical direction (see, e.g., Rabus and others, 1996). In a hydrological context it is appropriate to express $b$ as a water-equivalent thickness (and $\dot{b}$ as a water-equivalent thickness per time), but in the context of glacier dynamics or geodetically measured balance an ice-equivalent thickness is usually more appropriate. The latter will be our convention. For the glacier-wide balance and balance rates we use $B$ and $\dot{B}$, in ice-equivalent volume and volume per time. Balance quantities on the reference surface are designated with primes. Table 1 lists the variables used in this paper along with definitions and typical units.

\section{Definition of the conventional and reference-surface glacier-wide balance rates}

The actual surface is what one would find by visiting a glacier, and this surface is continuously changing. The reference surface is defined at one point in time and never changes. The relationship between conventional specific balance rate, $\dot{b}$, and reference-surface specific balance rate, $\dot{b}^{\prime}$, is simple if the reference and actual surfaces are close enough that the balance rate varies linearly in the vertical direction between them. Then

$$
\dot{b}=\dot{b}^{\prime}+\dot{G}\left(Z-Z^{\prime}\right),
$$

where the upper-case symbols $Z$ and $Z^{\prime}$ denote the elevations of the actual and reference surfaces at a given point in the map plane, and $\dot{G}$ is the vertical derivative of the balance rate there. (The lower-case symbol $z$ will represent the independent variable of elevation.) In the general case, all of these quantities may vary with horizontal position in the map plane. We call the derivative $\dot{G}$ the "balance-rate gradient", although it is only the vertical component of the mathematical gradient. Because of the linearity assumption, $\dot{G}=\dot{G}^{\prime}$.

Next we present expressions for the glacier-wide conventional and reference-surface balance rates, $\dot{B}$ and $\dot{B}^{\prime}$. In the case where a topographic map (or equivalently a digital elevation model) or an area distribution function (the amount of area per elevation interval of the actual surface) is available then the glacier-wide balance rates can be computed directly. These computations are often performed in practice by numerical summation methods, but we present them here in analytic form. If it is an adequate approximation to express the specific balance rate as a function of elevation $z$ only, the conventional rate is

$$
\dot{B}=\int_{\mathcal{Z}} \mathcal{A} \dot{b} \mathrm{~d} z,
$$

where $\mathcal{A}$ is the area distribution function. The integration is over $\mathcal{Z}$, the elevation range of the glacier. $\mathcal{A}$ and $\mathcal{Z}$ may vary with time. This is a familiar expression except that it deals with the instantaneous balance rate, rather than the balance accumulated during a specified time interval. The corresponding reference surface quantity is

$$
\dot{B}^{\prime}=\int_{\mathcal{Z}^{\prime}} \mathcal{A}^{\prime} \dot{b}^{\prime} \mathrm{d} z,
$$

where $\mathcal{A}^{\prime}$ is the area distribution function obtained from the reference surface map. This integration is over $\mathcal{Z}^{\prime}$, the elevation range of the reference glacier. $\mathcal{A}^{\prime}$ and $\mathcal{Z}^{\prime}$, unlike $\mathcal{A}$ and $\mathcal{Z}$, do not vary with time since the reference surface does not change. Assuming that the balance rate expressed as a function of elevation is not influenced significantly by changes in the glacier surface, $\dot{b}$ can be used in place of $\dot{b}^{\prime}$ in Equation (3). This assumption may tend to break down near the transient snowline and near the edges of the glacier.

If the specific balance rate as a function of map position cannot be adequately approximated as a function of elevation then Equations (2) and (3) are replaced by

$$
\dot{B}=\int_{A} \dot{b}(x, y) \mathrm{d} A
$$

and

$$
\dot{B}^{\prime}=\int_{A^{\prime}} \dot{b}^{\prime}(x, y) \mathrm{d} A,
$$

where $A^{\prime}$ is the map area of the reference surface and $x$ and $y$ are the map coordinates. The integrations are carried out over the map projection of the actual surface in Equation (4) and the reference surface in Equation (5). Thus the integrands, $\dot{b}(x, y)$ and $\dot{b}^{\prime}(x, y)$, are evaluated on the actual and reference surfaces, respectively. $A^{\prime}$, unlike $A$, does not vary with time. Although the reference-surface specific balance rate cannot be directly measured except when the 
actual surface is the reference surface, $\dot{b}^{\prime}(x, y)$ can be computed by Equation (1). Equation (4) is the general expression for evaluating the conventional glacier-wide balance except, as in Equation (2), it deals with the balance rate.

\section{A relation between conventional and reference-surface glacier-wide balance rates}

Equation (1) relates the specific balances on the conventional and reference surfaces. We next consider the glacierwide balances and show how they can be expressed in terms of the difference in area and volume between the actual and reference glaciers.

We begin with the case of a glacier which has advanced relative to its reference state; the results will then be generalized to cover retreat as well. Equation (4) can be rewritten as

$$
\begin{aligned}
& \dot{B}=\int_{A} \dot{b} \mathrm{~d} A \\
& \dot{B}=\int_{A^{\prime}} \dot{b} \mathrm{~d} A+\int_{\Delta A} \dot{b} \mathrm{~d} A,
\end{aligned}
$$

where $\Delta A$ is the difference between the actual and reference surface map areas, $A-A^{\prime}$ (Figure 1 shows the reference and actual surfaces and some related items). The first term on the righthand side of Equation (6) can be evaluated by substituting Equation (1) into the integrand, and applying Equation (5). The second term on the right can be calculated using a variation of Equation (1), whereby $\dot{b}=\dot{b_{\mathrm{r}}}+\dot{G}\left(Z-Z_{\mathrm{r}}\right)$. The "r" subscript signifies evaluation at the elevation of the glacier bed or the elevation of the ground exposed by retreat (Fig. 1); we call this surface the bedrock surface, although it may actually be till or some other material. $\dot{b}_{\mathrm{r}}$ is found at the corresponding elevation on the specific balance-rate curve, even though a specific balance cannot be measured on an ice-free surface. In the area between the reference and actual termini, $\Delta A$, the elevation of the reference surface, $Z^{\prime}$, is undefined, so we prescribe it to be identical to the bedrock surface elevation, $Z_{\mathrm{r}}$, at the same horizontal position (Fig. 1). Then, after minor rearrangement and combination of terms, Equation (6) becomes

$$
\dot{B}=\dot{B}^{\prime}+\int_{A} \dot{G}\left(Z-Z^{\prime}\right) \mathrm{d} A+\int_{\Delta A} \dot{b_{\mathrm{r}}} \mathrm{d} A .
$$

A similar equation, with the first integral carried out over $A^{\prime}$ (not $A$ ), is obtained from Equation (5) if the glacier has retreated.

In the case of retreat a few points should be noted. The surface of integration in the last term of Equation (7), $\Delta A$, is negative by definition. Also, within $\Delta A$ we define $Z \equiv Z_{\mathrm{r}}$, instead of $Z^{\prime} \equiv Z_{\mathrm{r}}$, in order to derive Equation (7). Finally, the balance curve must be extrapolated not only below the lowest measured point (as in the case of advance), but also beyond the actual glacier terminus to the reference terminus.

Equation (7) can be written in the simple form,

$$
\dot{B}=\dot{B}^{\prime}+\dot{G}_{\mathrm{e}} \Delta V+\dot{b}_{\mathrm{e}} \Delta A,
$$

where

$$
\dot{G}_{\mathrm{e}} \equiv \frac{\int_{A} \dot{G}\left(Z-Z^{\prime}\right) \mathrm{d} A}{\int_{A}\left(Z-Z^{\prime}\right) \mathrm{d} A}=\frac{\int_{A} \dot{G}\left(Z-Z^{\prime}\right) \mathrm{d} A}{\Delta V}
$$

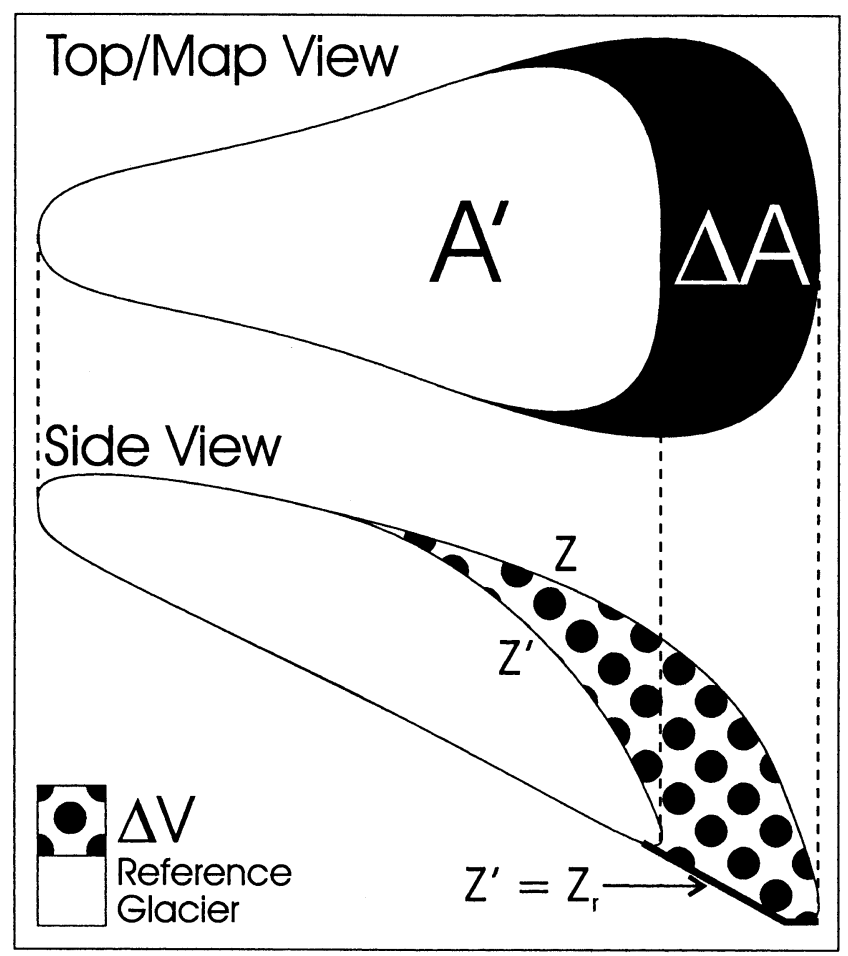

Fig. 1. Schematic of a glacier which has advanced since the reference surface was defined. $A^{\prime}$ is the map area of the reference surface; $\Delta A$ is the change in map area due to advance; $\Delta V$ is the increase in volume; $Z, Z^{\prime}$ and $Z_{\mathrm{r}}$ are the elevations of the conventional, reference and bedrock surfaces, respectively.

and

$$
\dot{b}_{\mathrm{e}} \equiv \frac{\int_{\Delta A} \dot{b}_{\mathrm{r}} \mathrm{d} A}{\int_{\Delta A} \mathrm{~d} A}=\frac{\int_{\Delta A} \dot{b}_{\mathrm{r}} \mathrm{d} A}{\Delta A} .
$$

Equation (8) is identical to Equation (7) but lends itself to approximations in $\dot{G}_{\mathrm{e}}$ and $\dot{b}_{\mathrm{e}}$. $\dot{G}_{\mathrm{e}}$ is the average of $\dot{G}$ over the entire glacier weighted to emphasize areas of large thickness change. $\dot{b}_{\mathrm{e}}$ is the average of $\dot{b}_{\mathrm{r}}$ over $\Delta A . \Delta V$ is the difference between the actual and reference volumes $\left(V-V^{\prime}\right)$, as shown in Figure 1; $\Delta A$ is the corresponding difference in map area as defined previously. In case of retreat each integration in Equation (9) is over $A^{\prime}$ instead of $A$, making Equation (8) valid in both advance and retreat.

Equation (8) states that the difference between the reference-surface and conventional glacier-wide balance rates can be expressed by two terms, one accounting for the change in surface elevation $\left(\dot{G}_{\mathrm{e}} \Delta V\right.$, the "volume" or the "surface elevation" term) and one for the change in area, especially near the terminus ( $\dot{b}_{\mathrm{e}} \Delta A$, the "area" term). These are usually of opposite sign since $\dot{b}_{\mathrm{e}}<0$.

Transformation between conventional and reference-surface glacier-wide annual balances

So far we have dealt only with balance rates. This was to avoid any ambiguity due to time-varying surface characteristics. A balance rate, because it is defined at a specific point in time, is associated with a specific glacier surface geometry at that same moment. The balance rate at any moment in time is not likely to be a simple function of position or elevation because passing storms or instantaneous wind patterns do not follow smooth patterns. For this reason, balance rates are generally averaged over either a season or a year; 
on these time-scales definite patterns in accumulation and ablation are apparent. Nye (1965) chose to approximate the time-varying balance rate by an average annual value. This is possible when changes in glacier geometry occur on timescales much greater than 1 year, as Nye (1965) found for his study of South Cascade Glacier. Using this approximation, the time-integrated form of Equation (8) can be expressed in terms of annual balances rather than balance rates by merely dropping the time derivatives. Then the conventional annual balance for the balance year is

$$
B=B^{\prime}+G_{\mathrm{e}} \Delta V+b_{\mathrm{e}} \Delta A .
$$

Each quantity in Equation (11) (e.g. $B, G_{\mathrm{e}}$ or $\Delta V$ ) is evaluated for the balance year in question. $G_{\mathrm{e}}$ and $b_{\mathrm{e}}$ are found by corresponding time-integrated forms of Equations (9) and (10). Values for $\Delta V$ and $\Delta A$ can be taken (for simplicity) to be those values found at the end of the balance year; note that they are both defined as the changes relative to the reference surface, and not relative to the beginning of the balance year.

The cumulative balance from year one to year $n$ is then

$$
B_{n}^{(\text {cumul })}=\sum_{j=1}^{n} B_{j}
$$

where $B_{j}$ is the conventional annual balance for the $j$ th year, as obtained from Equation (11). Reference-surface glacierwide cumulative balances can be calculated by an analogous equation.

$\Delta V_{n}$ is the total change in volume from $t=0$ to the end of year $n$. $B_{n}^{\text {(cumul) }}$ is the ice-equivalent volume change over the same time interval. We approximate $\Delta V_{n}$ by $B_{n}^{(\text {cumul })}$ in order to solve explicitly for the conventional glacier-wide annual balance, $B_{n}$ :

$$
B_{n}=\frac{1}{1-\left(G_{\mathrm{e}}\right)_{n}}\left[B_{n}^{\prime}+\left(G_{\mathrm{e}}\right)_{n} \sum_{j=1}^{n-1} B_{j}+\left(b_{\mathrm{e}}\right)_{n} \Delta A_{n}\right] \text {. }
$$

This is the required transformation between a referencesurface annual balance and a conventional annual balance.

\section{Geodetic corrections}

By our convention, a geodetic balance is the ice-equivalent volume change determined by comparing two maps. This could equivalently be called the geodetic cumulative balance over the interval from the first map to the second. Alternatively, airborne laser surface profiling techniques can also be used to measure glacier volume change (Echelmeyer and others, 1996). If more than two maps are available then the geodetic balances, measured between each consecutive pair of maps, can be summed to form a series of geodetic cumulative balances, each one representing the total change in iceequivalent volume since the first map in the series. Such a geodetic cumulative balance series is less subject to the accumulation of systematic errors, and is thus usually more accurate than a glaciologically measured cumulative balance. The accuracy of a geodetic balance is inherently limited by the quality of the maps used.

We can use a geodetic cumulative balance series (or even one long-term geodetic balance) to determine a correction for the conventional glacier-wide cumulative balance series by requiring that they agree (in a least-squares sense, if necessary) over the same time intervals. We apply this correction as a one- or two-parameter adjustment to the reference- surface glacier-wide annual balances. The two-parameter version is

$$
B_{n}^{\prime}(\text { correct })=c_{0}+c_{1} B_{n}^{\prime}(\text { measured })
$$

Initial values of the coefficients are estimated and then revised by an iterative process. Each iteration involves adjusting $c_{0}$ and $c_{1}$, transforming the "corrected" referencesurface annual balances via Equation (13), summing the transformed conventional annual values using Equation (12), and computing the root-mean-square ( $\mathrm{rms}$ ) deviation between the conventional and geodetic cumulative balance series. The iteration concludes when the deviation is minimized. A simple linear goal-seeking algorithm, available in some spreadsheets, is a useful tool for this procedure.

In the following example on South Cascade Glacier we make the corrections to the glacier-wide balances only. This is because we believe that the main systematic errors arise in the extrapolation and integration of the specific balances over the area of the glacier, and not in the specific balances themselves. Errors in extrapolation of specific balances near the terminus are particularly significant in both advance and retreat. They affect both conventional and referencesurface balance computations.

\section{Summary of the transformation method}

Before transforming reference-surface balances into conventional balances, the following information must be gathered:

$$
\text { the map that defines the reference surface }
$$$$
\text { all other available maps of the glacier }
$$

the specific balance curve for each year in the time series the measured glacier area and coordinates of the glacier boundary for each year

a map of the bedrock surface that falls within $\Delta A$.

The transformation then follows the procedure given in the form of a flow chart in Figure 2. The results are time series of reference-surface and conventional balances corrected to fit to the geodetic cumulative balances (if available). In the next section we apply this methodology to an example.

\section{APPLICATION TO SOUTH GASGADE GLACIER}

We need to choose a subject glacier in order to demonstrate the transformation between reference-surface and conventional balances. This glacier should have as many data available as possible, including a long time series of measurements, numerous repeat mappings, and easy access to the archived data. South Cascade Glacier fits these criteria. The abundance of information allows us to perform exact computations while learning to approximate those quantities that many mass-balance programs are not able to evaluate exactly. Such an abundance of data also makes it possible to compute conventional mass balances for most years without going through the transformation method we have described, and this has been done previously (Table 2; Krimmel, 1999b). Applying the transformation to South Cascade Glacier guided our development of the theory into a modus operandi and here serves to demonstrate the various steps involved. 


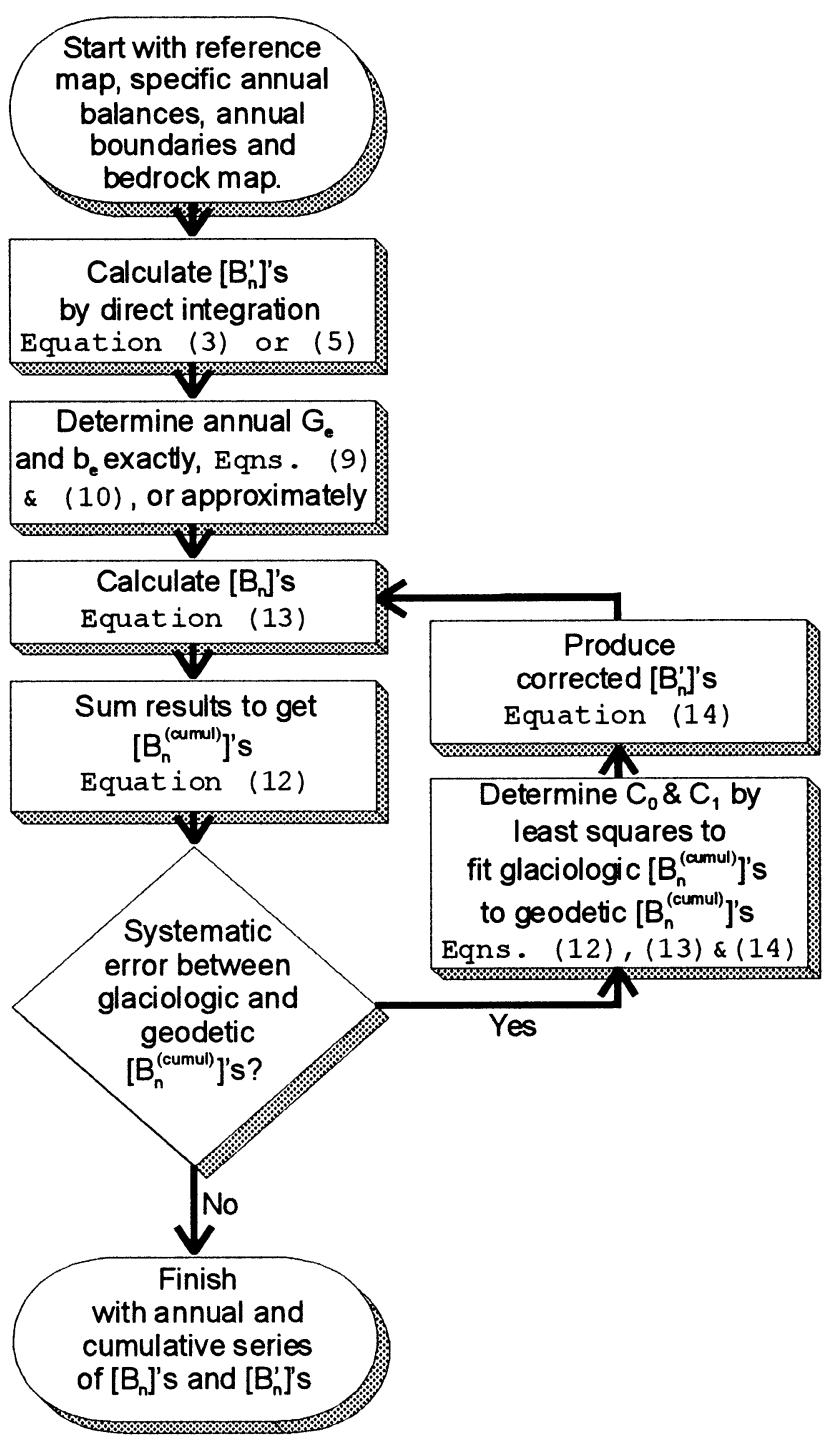

Fig. 2. Flow chart of the steps and equations used to compute reference-surface glacier-wide balances and transform them into conventional balances.

\section{Data}

South Cascade is a small glacier in the North Cascade Mountains (Meier and others, 1971). Its present area is about $2 \mathrm{~km}^{2}$. The temporal changes in its area (Fig. 3; Table 3) have been measured from ablation-zone outlines. Geodetic volume change has been determined over various time intervals by airborne photogrammetry (Krimmel, 1999a). The Appendix

Table 2. Density of balance-stake measurements, methods used for integration of previously published conventional glacierwide balances, and availability of air photos for South Cascade Glacier, as reported by Krimmel (1999b)

\begin{tabular}{|c|c|c|c|}
\hline $\begin{array}{l}\text { Time } \\
\text { interval }\end{array}$ & $\begin{array}{c}\begin{array}{c}\text { Balance- } \\
\text { stake density }\end{array} \\
\mathrm{km}^{-2}\end{array}$ & $\begin{array}{l}\text { Integration method used } \\
\text { in previous analyses }\end{array}$ & Air photos available \\
\hline $1958-73$ & $>10$ & $\begin{array}{c}\text { Gridding of } \\
\text { hand-contoured map }\end{array}$ & $1958,1961,1970$ \\
\hline 1974-82 & $2-3$ & $\begin{array}{c}\text { Gridding of } \\
\text { hand-contoured map }\end{array}$ & $\begin{array}{c}1975,1977,1979, \\
1980\end{array}$ \\
\hline 1983-85 & 0.5 & Correlation with earlier & 1985 \\
\hline $1986-97$ & $\begin{array}{c}\text { (1 index stake) } \\
0.5^{-}-3\end{array}$ & $\begin{array}{c}\text { balances (see Krimmel, 1989) } \\
\text { Grid index (see Krimmel, 1996) }\end{array}$ & 1986-97 \\
\hline
\end{tabular}

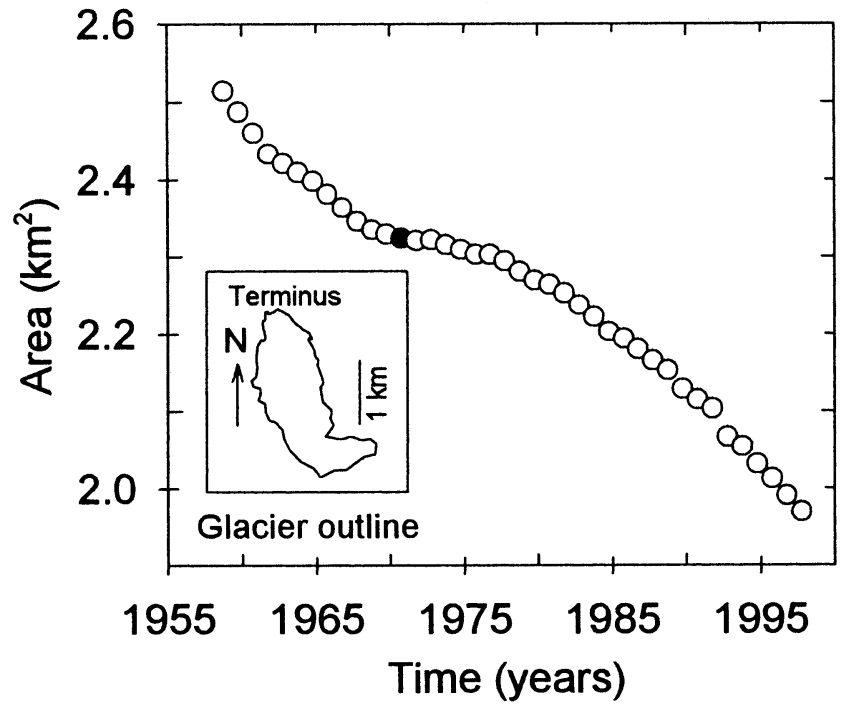

Fig. 3. South Cascade Glacier map area since September 1958, and an outline of the reference surface. The solid black circle represents the area at the time when the reference surface was defined (29 September 1970).

describes how we computed a series of geodetic cumulative balances from these volume-change measurements. It also describes how specific balance curves were fit to and extrapolated above and below the available field data. Figure 4 shows the geodetic cumulative balances. We plot glacier-wide balances primarily in units of volume. The secondary axis is scaled by a constant factor of $1 / A^{\prime}$ to yield a characteristic thickness change; this is more easily envisioned than volume change. This differs from the often used convention of plotting cumulative average specific balances, which introduces unnecessary errors in volume-change computations if a glacier's area is changing significantly during the time series.

Table 2 is a partial summary of the data available and the methods that were used by Krimmel and others to determine conventional glacier-wide annual balances from 1959 to 1997 (Krimmel, 1999b). Such a diversity of data-reduction methods introduces inconsistencies in the previously published conventional balance series. We reduce each year's data as consistently as possible, thereby eliminating some systematic errors. We use data only from 1970 to 1997 because consistent photogrammetric techniques were used during that period. The use of geodetic corrections, in the form of Equation (14), also makes our resulting series of conventional balances differ from those previously published.

\section{The exact transformation}

There are abundant data available for South Cascade, including many repeat mappings. In this section we use all of the available data to produce a nearly exact series of conventional balances. Afterwards we look at what can be done when fewer maps are available. The first step in the flow chart (Fig. 2) is to compute the reference-surface glacier-wide annual balance, $B^{\prime}$, for each year. Taking the 29 September 1970 map (in the form of a digital elevation model) as our reference surface, these balances can be computed directly by Krimmel's (1996) grid-index method, using the same 1970 area distribution function for each year's calculation. The grid-index method is a numerical form of Equation (3) since the specific balance is approximated as a function of elevation only. For a given year the reference-surface average specific 


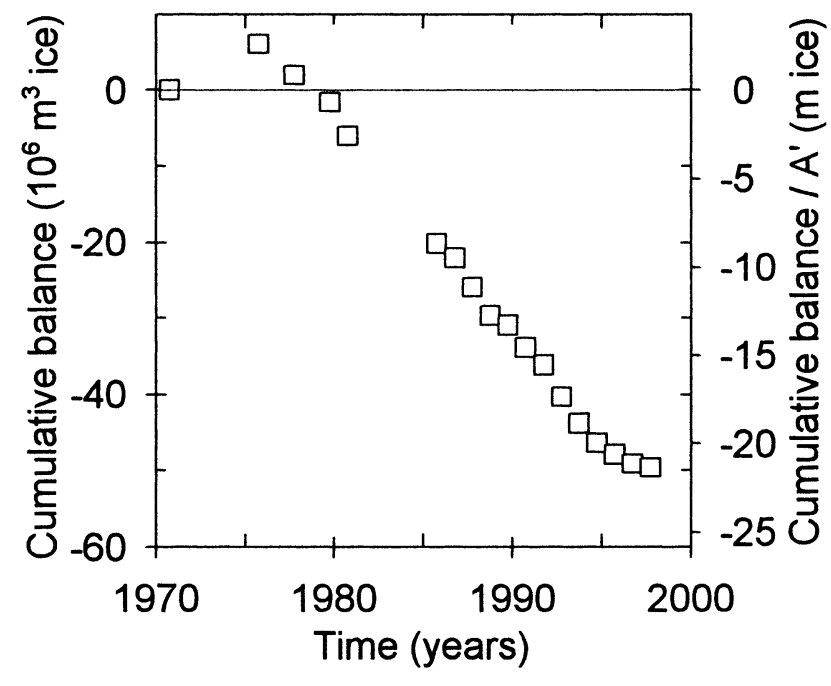

Fig. 4. Geodetic cumulative balances for South Cascade Glacier since 1970.

balance is $B^{\prime} / A^{\prime}$; from 1970 to 1997 the mean of the annual values for this quantity is $-0.95 \mathrm{~m}$ of ice.

Next, we compute $G_{\mathrm{e}}$ for each year using a form of Equation (9) without time derivatives. This requires an annually updated map and the reference surface map because both $Z$ and $Z^{\prime}$ are present. For those years when we have an updated map (1985-97), we perform numerical integration of the two terms in Equation (9). The product $G\left(Z-Z^{\prime}\right)$ is evaluated at each gridcell $\mathrm{d} A$ in the reference area $A^{\prime}$. The solid circles in Figure 5 a show the series of $G$ 's calculated in this manner. No trend with time is apparent, so from 1970 through 1984 we approximate $G_{\mathrm{e}}$ by the average of these latter results $\left(0.024 \mathrm{~m} \mathrm{~m}^{-1}\right.$ with an interannual standard deviation of $\left.0.004 \mathrm{~m} \mathrm{~m}^{-1}\right)$.

Evaluation of the $b_{\mathrm{e}}$ 's using Equation (10), again dropping the time derivatives, requires a map of bedrock elevations within $\Delta A$. This map can be created by several different methods. In case of retreat, a recent map should include these elevation data. Alternatively, a sampling of surveyed bedrock surface elevations which spans the $\Delta A$ region can be interpolated to approximate a topographic map there. These points may be surveyed during one field excursion or, as we chose to do in this example, assembled from the existing annual surveys of the terminus boundary. If the glacier has advanced then these data may already exist because the original map probably includes the subsequently covered bedrock surface in addition to the glacier itself.

The balance at the elevation of the bedrock surface, $b_{\mathrm{r}}$, is found on the appropriate year's balance curve for each cell $\mathrm{d} A$ in the $\Delta A$ region. The bedrock elevations from the interpolated topographic map do not vary with time, and the ablation zone outlines allow us to determine $\Delta A$ for each year. The solid circles in Figure $5 \mathrm{~b}$ are the calculated values of $b_{\mathrm{e}}$; they show a positive trend with time due to the incorporation of higher elevations (and thus less negative balances) into $\Delta A$ as the terminus retreats. The average annual value of $b_{\mathrm{e}}$ is $-6.16 \mathrm{~m}$ with an interannual standard deviation of $1.18 \mathrm{~m}$.

With all the necessary values of $B^{\prime}, G_{\mathrm{e}}, b_{\mathrm{e}}$ and $\Delta A$ known for every year, we now use Equation (13) to evaluate the conventional glacier-wide annual balances. Equation (12) is used

Table 3. South Cascade Glacier area, annual and cumulative reference-surface and conventional glacier-wide balances, and geodetic cumulative balances

\begin{tabular}{|c|c|c|c|c|c|c|}
\hline \multirow{3}{*}{ Balance year } & \multirow{3}{*}{$\begin{array}{c}\text { Area } \\
10^{6} \mathrm{~m}^{2}\end{array}$} & \multicolumn{2}{|c|}{ Annual } & \multicolumn{3}{|c|}{ Cumulative } \\
\hline & & Reference-surface & Conventional & Reference-surface & Conventional & Geodetic \\
\hline & & $10^{6} \mathrm{~m}^{3}$ ice & $10^{6} \mathrm{~m}^{3}$ ice & $10^{6} \mathrm{~m}^{3}$ ice & $10^{6} \mathrm{~m}^{3}$ ice & $10^{6} \mathrm{~m}^{3}$ ice \\
\hline 1970 & 2.32 & -4.30 & -4.30 & 0.00 & 0.00 & 0.00 \\
\hline 1971 & 2.32 & 0.71 & 0.75 & 0.71 & 0.75 & \\
\hline 1973 & 2.32 & -4.24 & -4.16 & 0.78 & 1.05 & \\
\hline 1974 & 2.31 & 3.03 & 3.22 & 3.81 & 4.27 & \\
\hline 1975 & 2.30 & -0.32 & -0.10 & 3.49 & 4.17 & 6.05 \\
\hline 1976 & 2.30 & 2.94 & 3.25 & 6.43 & 7.42 & \\
\hline 1977 & 2.30 & -4.88 & -4.63 & 1.55 & 2.79 & 1.99 \\
\hline 1978 & 2.28 & -1.80 & -1.42 & -0.25 & 1.37 & \\
\hline 1979 & 2.27 & -6.73 & -6.38 & -6.99 & -5.02 & -1.63 \\
\hline 1980 & 2.26 & -3.68 & -3.52 & -10.67 & -8.54 & -6.06 \\
\hline 1982 & 2.24 & -1.14 & -0.83 & -14.66 & -12.03 & \\
\hline 1983 & 2.22 & -2.81 & -2.42 & -17.47 & -14.46 & \\
\hline 1984 & 2.20 & 0.05 & 0.34 & -17.43 & -14.12 & \\
\hline 1985 & 2.19 & -3.56 & -3.25 & -20.99 & -17.37 & -20.13 \\
\hline 1986 & 2.18 & -2.32 & -2.11 & -23.32 & -19.48 & -22.02 \\
\hline 1987 & 2.17 & -6.66 & -6.18 & -29.98 & -25.65 & -25.91 \\
\hline 1988 & 2.15 & -4.54 & -4.28 & -34.52 & -29.93 & -29.62 \\
\hline 1989 & 2.13 & -3.26 & -3.11 & -37.77 & -33.05 & -30.90 \\
\hline 1990 & 2.12 & -0.86 & -0.70 & -38.63 & -33.74 & -33.84 \\
\hline 1991 & 2.10 & -0.20 & -0.11 & -38.83 & -33.85 & -36.13 \\
\hline 1992 & 2.07 & -6.56 & -5.71 & -45.39 & -39.56 & -40.28 \\
\hline 1993 & 2.05 & -3.21 & -2.82 & -48.60 & -42.38 & -43.82 \\
\hline 1994 & 2.03 & -5.18 & -4.48 & -53.78 & -46.85 & -46.37 \\
\hline 1995 & 2.01 & -3.29 & -2.75 & -57.07 & -49.60 & -47.88 \\
\hline 1996 & 1.99 & -0.68 & -0.38 & -57.75 & -49.98 & -49.12 \\
\hline 1997 & 1.97 & -0.10 & 0.25 & -57.85 & -49.73 & -49.62 \\
\hline
\end{tabular}




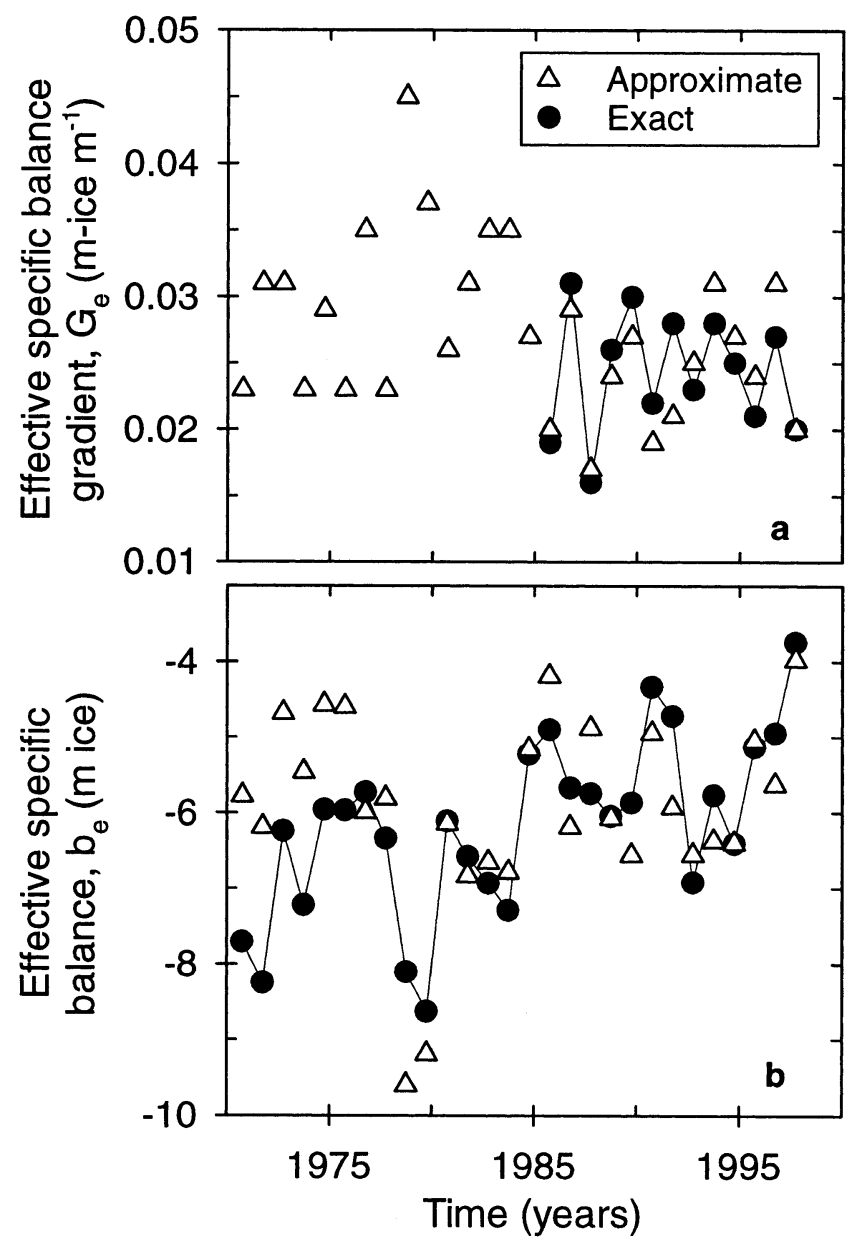

Fig. 5. (a) Exact and approximate values of $G_{\mathrm{e}}$ for South Cascade Glacier. Each year the approximate value is taken to be 90\% of the value of $G$ at $1733 \mathrm{~m}$. (b) Exact and approximate values of $b_{\mathrm{e}}$ for South Cascade Glacier. Each year the approximate value is taken to be $0.75 b_{\mathrm{t}}$, where $b_{\mathrm{t}}$ is the specific balance at the elevation of the actual glacier terminus.

to calculate the cumulative balances, and these can be compared with geodetic cumulative balances over the same time interval. In the case of South Cascade Glacier the ratio of the geodetic to the glaciologic cumulative balances over the entire interval 1970-97 is consistently about 1.5, as noted by Krimmel when analyzing his reported glaciologic and geodetic balances (Krimmel, 1999a). Krimmel (1989) considered whether the difference over an earlier interval could be due in part to the breakdown of Sorge's law (Sorge, 1935). Our correction (see Appendix) takes this into account, yet there is still a divergence between the two balances. The divergence we find falls within the range of values found by other massbalance programs for their subject glaciers. For example, we compared glaciologic and geodetic measurements for eight glaciers described in the proceedings of the August 1998 Tarfala meeting on "Methods of Mass Balance Measurements and Modelling". Of those eight comparisons, one showed nearly perfect agreement (Kuhn and others, 1999), while the ratio of geodetic to glaciologic measurements in the rest ranged from -1.7 to +1.7 (e.g. Trabant and March, 1999).

The next step is to determine the coefficients in Equation (14) by minimizing the rms error between the conventional glaciologic cumulative balances and the available geodetic cumulative balances. These were found to be $c_{0}=-0.35 \times 10^{6}$ $\mathrm{m}^{3}$ and $c_{1}=1.16$. After the reference-surface glacier-wide balances were corrected, they were substituted back into Equation (13) to produce corrected conventional balances.

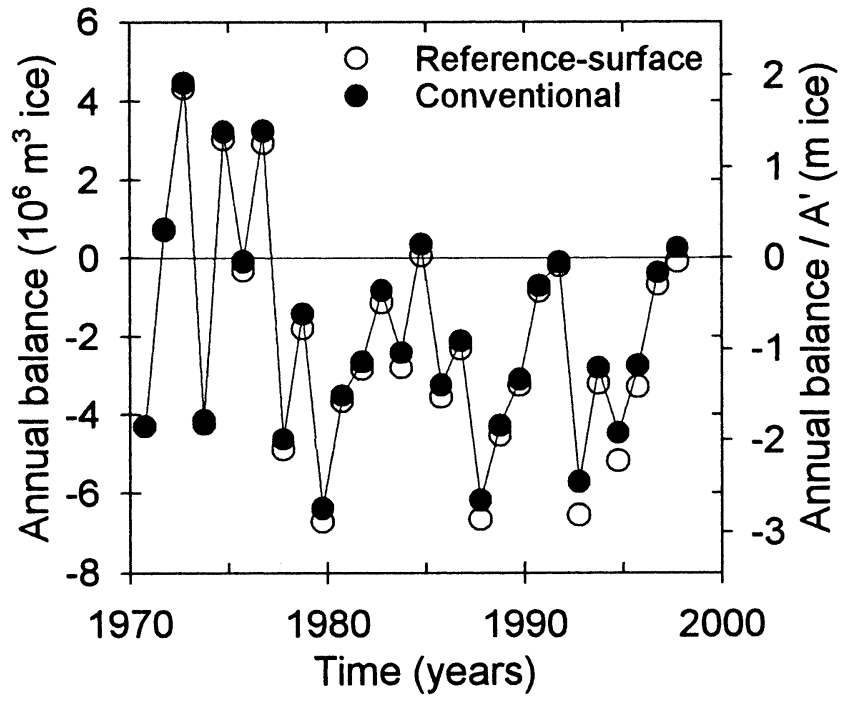

Fig. 6. Conventional and reference-surface annual balances for South Cascade Glacier.

The final conventional and reference-surface annual balances are shown in Figure 6, the cumulative balances (including geodetic) are shown in Figure 7 and all of the data plotted are listed in Table 3, along with the annual glacier areas. The differences between the reference-surface and conventional annual balances are fairly small over this time interval, but the differences in the cumulative balances are significant. Both differences will continue to grow with time if the current climatic conditions persist.

\section{Approximations for the exact transformation}

Now that we have some experience with calculations when there are bountiful data, we are ready to see what approximations would be necessary on a glacier with fewer or no repeat mappings. Some mass-balance programs will have maps for some years other than just the reference year. For these years, $G_{\mathrm{e}}$ and $b_{\mathrm{e}}$ can be evaluated and trends may appear from which to estimate values for the unmapped years. The quality of the estimates made will depend greatly on how many data exist; without any updated maps these approximations will be difficult or impossible to make. This section contains potential estimates of $G_{\mathrm{e}}$ and $b_{\mathrm{e}}$ which we found to work with our data; some will be applicable to other glaciers, while others will not. Tests of what works best will be necessary for each mass-balance program.

We find the best approximation of $G_{\mathrm{e}}$ to be 0.9 times the value of the specific balance gradient at $1733 \mathrm{~m}$ on South Cascade $\left(r^{2}=0.58\right)$. This corresponds with an elevation a little less than half of that from the terminus to the equilibrium line. Figure 5a shows a comparison of the exact and approximate values for $G_{\mathrm{e}}$.

As mentioned above, calculation of $b_{\mathrm{e}}$ does not require annual glacier maps. It does require annual terminus outlines and the reference terminus outline to define the $\Delta A$ region, a bedrock map in the vicinity of the terminus, and specific balances low on the glacier (in case of advance) or extrapolated below the actual terminus (in case of retreat). Two important annual field measurements in this case are the specific balance near the terminus and a survey of the terminus boundary. If even a rudimentary bedrock map is impossible to produce by the methods previously mentioned, then approximations to $b_{\mathrm{e}}$ must be used. Our exact $b_{\mathrm{e}}$ term appears to have a slight time dependence as seen in 


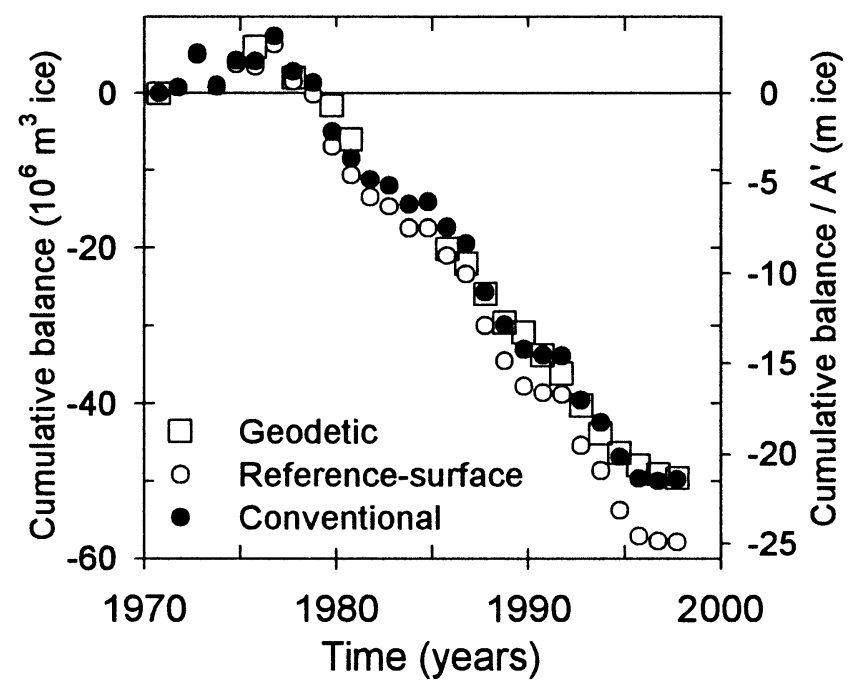

Fig. 7. Conventional, reference-surface and geodetic cumulative balances for South Cascade Glacier since 1970.

Figure 5b, for the reason mentioned previously. Thus we choose an approximation that is relative to the specific balance at the actual terminus elevation, $b_{\mathrm{t}}$, for each year. In this case we find $b_{\mathrm{e}}=0.75 b_{\mathrm{t}}$ is the best substitution $\left(r^{2}=\right.$ 0.50 , but from 1976 to $\left.1997 r^{2}=0.80\right)$. Figure $5 \mathrm{~b}$ shows the approximate values for $b_{\mathrm{e}}$.

Starting with the same geodetically corrected referencesurface balances as in the exact case and using the approximate values for $G_{\mathrm{e}}$ and $b_{\mathrm{e}}$ just described, we compute the approximate conventional balances using Equation (13). The correlation between the exact and approximate annual balances is excellent, with $r^{2}=0.998$, and there is a difference in the average values of only $0.4 \%$. The exact and approximate cumulative balances also agree almost exactly. Thus, the approximate method potentially yields results quite close to the exact method while using fewer observations as input. If the South Cascade Glacier mass-balance program no longer had the resources to map the glacier annually, then both of these approximations would aid in the continuation of an accurate time series of conventional mass balances.

The best approximations for $G_{\mathrm{e}}$ and $b_{\mathrm{e}}$ will most likely be different on other glaciers due to the surface and bed geometries, the shape of the specific balance curve, and the amount of advance or retreat. If there is at least one repeat mapping then we suggest calculating $G_{\mathrm{e}}$ for that (those) year $(\mathrm{s})$ and looking for a similar connection with elevation. Otherwise, we recommend using the specific balance gradient at an elevation halfway between the terminus and the equilibrium line. As mentioned above, other mass-balance programs are less likely to require an approximate form of $b_{\mathrm{e}}$. In case some approximation is required, then $0.75 b_{\mathrm{t}}$ is probably the best choice.

\section{Cumulative effects of geometry changes on mass balance}

The 1997 reference-surface cumulative balance since 1970 is $16 \%$ more negative than the conventional one. This difference is due in part to recession of the terminus, which reduces the size of the ablation area and brings the glacier closer to equilibrium, and in part to lowering of the surface, which shifts the glacier into a more negative balance regime and counters some of the effects of the area change. Figure 8 is a plot of the annual values of both the area and volume terms

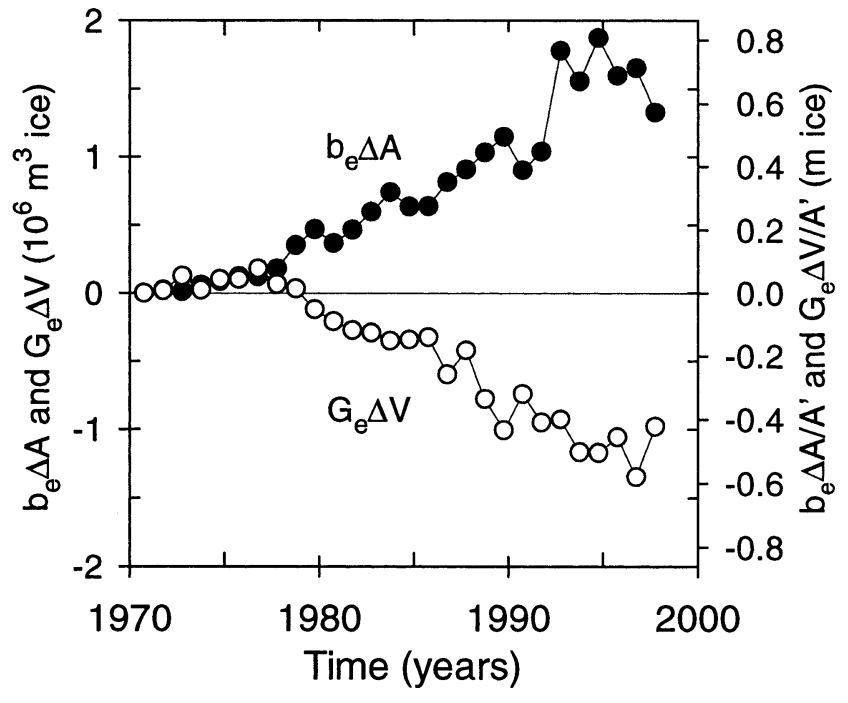

Fig. 8. South Cascade Glacier annual values for the volume and area terms in Equation (11).

from the exact transformation. From 1970 to 1997 the cumulative effect of the volume term was $60 \%$ as large as that of the area term, and it was of opposite sign.

\section{DISGUSSION}

\section{What measurements are needed?}

In order to apply these ideas, mass-balance researchers need to measure the following, either remotely or in the field:

annual terminus position and elevation as far up the sides and of such spatial resolution as is practical or necessary for two applications: to quantify area changes and to contribute to a bedrock map

bedrock elevations at points previously unsurveyed but within $\Delta A$

specific annual mass balance as low on the glacier as possible because of the rapidly varying balance curve there.

These measurements, in conjunction with the data-reduction methods presented here, can reduce systematic errors in the derived balances.

Some programs will be able to remap the glacier only infrequently, and the surface may change significantly between successive maps. In order to compute the most accurate conventional balances possible, the newest map (assuming map accuracy is comparable) should be used. In the intervening years before the next map is made, our methodology will again have to be called upon. The original reference-surface map should still be used when reporting reference-surface balances so that its time series is both continuous and consistent.

\section{Choice of the reference surface}

One of our underlying points is that variations in the surface over which specific balance measurements are integrated directly affect the glacier-wide balance. By the same logic, the choice of the reference surface will affect the referencesurface glacier-wide balance. With the help of Equation (11) it can be shown that the difference between the glacier-wide annual balances on two different reference surfaces will be approximately constant over the years, with only small fluctuations due to interannual variations in $G_{\mathrm{e}}$ and $b_{\mathrm{e}}$. Cumulative 
balances are even more sensitive to the choice of reference surface. The trend in the difference between the glacier-wide cumulative balances on two different reference surfaces will grow approximately linearly with time. Logically it makes the most sense to choose the reference surface to be the glacier surface at the beginning of the time series, but whatever the choice the reference surface must be clearly defined.

A large difference between the chosen reference surface and the actual surface reduces the accuracy of Equation (1) because the linearity assumption upon which the equation was based is unlikely to remain valid. Another assumption we made was that changes in the glacier surface do not significantly affect balance rate as a function of elevation. This allowed us to substitute $\dot{b}$ for $\dot{b}^{\prime}$ in Equation (3), but large deviations between the reference and actual surfaces weaken this assumption as well. Temporal and spatial variations in environmental variables, including surface albedo, solar input, wind patterns and proximity to rock surfaces, help to undermine both of these assumptions.

\section{Relevance of the reference-surface balance to glacier dynamics and climate studies}

The concepts described here can be used as the basis for a new and simple approach to the theory of glacier response to climate. This results when Equation (8), a statement of the conservation of mass, is combined with a functional relationship between area and volume which specifies the dynamics of flow (Harrison and others, 2001).

These ideas also have a bearing on climate studies. By removing the effects of changing surface configuration on mass balance, reference-surface balances are more closely related to trends in climate than are conventional balances. The following example demonstrates that conventional mass balance is not always well correlated with climate variations. If a glacier initially in equilibrium experiences a permanent step increase in summer temperature, by the mechanisms of glacier flow it will usually adjust its length and thickness until equilibrium with the new climate is reached. The initial and final conventional balance rates are the same (zero), but the initial and final surfaces, and the climate, are different. This illustrates the non-unique relationship between conventional balance and climate, and one of the difficulties in connecting the two. The reference-surface balance on the same glacier, under the same conditions, will experience a permanent step decrease coincident with the climate change. Because the reference surface does not adjust itself, the reference-surface balance will continue to reflect the permanent change in climatic conditions.

\section{CONGLUSIONS}

We have presented a method by which glaciologists can compute a change in glacier mass from specific balance measurements, without the benefit of an up-to-date map. Changes both in glacier area (the area term in Equation (11)) and in surface elevation (the volume term in Equation (11)) since the time when an older map was made must be taken into account. Both of these terms are vital aspects of glacier response to climatic forcing (Harrison and others, 2001). In addition, reference-surface balances which measure the balance on an unchanging surface, and not conventional balances, are required for studies of glacier dynamics and climate change. For this reason, reference-surface balances should be routinely reported along with conventional balances.

A separate and possibly more significant issue is the often observed difference between geodetic and glaciologic measurements of a glacier's mass balance. To this end, we believe that the first priority of mass-balance programs should be to understand and control the large systematic errors that seem to plague most glacier-wide balance estimates made by glaciologic methods.

\section{AGKNOWLEDGEMENTS}

This work was supported by the U.S. National Science Foundation program under grant No. OPP97-07515. We would like to thank D. Trabant, R. March, J. Sapiano and J. Schmok for their assistance and input. T. Jóhannesson was helpful beyond the call of duty, not only performing as an extraordinary scientific editor, but also serving as one of the peer reviewers. His insights into this topic were an invaluable help in redirecting the focus of this paper. The three other reviewers, M. Kuhn, R. LeB. Hooke and one reviewer who was anonymous, provided extensive helpful comments as well.

\section{REFERENCES}

Echelmeyer, K. A. and 8 others. 1996. Airborne surface profiling of glaciers: a case-study in Alaska. 7. Glaciol., 42 (142), 538-547.

Harrison, W. D., D. H. Elsberg, K. A. Echelmeyer and R. M. Krimmel. 2001. On the characterization of glacier response by a single time-scale. 7. Glaciol., 47(159), 659-664.

Krimmel, R. M. 1989. Mass balance and volume of South Cascade Glacier, Washington, 1958-1985. In Oerlemans, J., ed. Glacier fluctuations and climatic change. Dordrecht, etc., Kluwer Academic Publishers, 193-206.

Krimmel, R. M. 1996. Glacier mass balance using the grid-index method. CRREL Spec. Rep. 96-27, 62-68.

Krimmel, R. M. 1999a. Analysis of difference between direct and geodetic mass balance measurements at South Cascade Glacier, Washington. Geogr. Ann., 81A(4), 653-658.

Krimmel, R. M. 1999b. Water, ice, meteorological and speed measurements at South Cascade Glacier, Washington, 1998 balance year. U.S. Geol. Surv. Water-Resour. Invest. Rep. 99-4049.

Kuhn, M., E. Dreiseitl, S. Hofinger, G. Markl, N. Span and G. Kaser. 1999. Measurements and models of the mass balance of Hintereisferner. Geogr. Ann., 81A(4), 659-670.

Meier, M. F., W.V. Tangborn, L. R. Mayo and A. Post. 1971. Combined ice and water balances of Gulkana and Wolverine Glaciers, Alaska, and South Cascade Glacier, Washington, 1965 and 1966 hydrologic years. U.S. Geol. Surv. Prof. Pap. 715-A.

Nye, J. F. 1965. A numerical method of inferring the budget history of a glacier from its advance and retreat. F. Glaciol., 5(41), 589-607.

Østrem, G. and M. Brugman. 1991. Glacier mass-balance measurements. A manual for field and office work. Saskatoon, Sask., Environment Canada. National Hydrology Research Institute. (NHRI Science Report 4.)

Rabus, B., W. D. Harrison and K. A. Echelmeyer. 1996. Correspondence. Comments on "The use of planimetric surface area in glacier massbalance calculations: a potential source of errors" by Jacobsen and Theakstone. 7. Glaciol., 42(142), 588.

Sorge, E. 1935. Glaziologische Untersuchungen in Eismitte. In Brockamp, B., H. Jülg, F. Loewe and E. Sorge, Wissenschaftliche Ergebnisse der Deutschen Grönland-Expedition Alfred Wegener 1929 und 1930/1931. Band III. Glaziologie. Leipzig, F. A. Brockhaus, 62-270.

Trabant, D. C. and R. S. March. 1999. Mass-balance measurements in Alaska and suggestions for simplified observations programs. Geogr. Ann., 81A(4), 777-789.

\section{APPENDIX}

The Appendix includes details of the methods used for balance calculations on South Cascade Glacier. 


\section{Computing a geodetic cumulative balance series}

Differencing of glacier maps yields geodetic volume changes which we want to use to correct the ice-equivalent glaciologic balances. We must adjust the geodetic volume changes because Sorge's law, which states that the density structure of a glacier stays constant with time under certain conditions (Sorge, 1935), is not strictly valid on most glaciers, especially during periods of thinning (Krimmel, 1989). During periods of negative balance both firn and ice are lost at middle elevations, while in the upper accumulation zone and the lower ablation zone, changes in volume are assumed to be of ice only. Because firn has a lower density than ice, the average density of lost material at mid-elevations is between those of firn and ice. Krimmel (1989) estimated the fractional areas for these three elevation zones on South Cascade Glacier as such: low (ice) $=\frac{1}{4}$, mid (firn and ice) $=\frac{1}{2}$, and high (ice) $=\frac{1}{4}$. He then reported a firn density profile which shows an average of approximately $700 \mathrm{~kg} \mathrm{~m}^{-3}$. With this, and an ice density of $900 \mathrm{~kg} \mathrm{~m}^{-3}$, we compute the glacier-wide weighted average density of the lost volume to be $850 \mathrm{~kg} \mathrm{~m}^{-3}$. This modest $5.5 \%$ correction in density decreases the magnitude of the geodetic volume changes (of mixed firn and ice) on South Cascade Glacier, yielding ice-equivalent balances. These balances are summed over time to give a geodetic cumulative balance series. Because of this density correction, substituting the geodetically corrected $B^{\text {(cumul) }}$ for $\Delta V$ in Equation (13) undervalues the volume term by $5.5 \%$, but for simplicity we do not correct for this.

\section{Extrapolation of balance-elevation curves}

To evaluate the time-integrated form of Equation (3), it is necessary to fit balance-elevation curves to the field data and to extrapolate these curves to the positions of the terminus and head of the reference glacier. The curves thus extend below and above the range of field measurements made each year. To do this we usually fit a quadratic curve to the measured specific balances. In some years the paucity of data does not permit a fit to be determined, so either a constant offset is added to an average balance curve to fit the existing data (twice), or the quadratic fit is limited to some maximum balance to yield a reasonable curve (four times). We find the computed reference-surface balances to be relatively unaffected by reasonable variations in the extrapolation of the measured balance-elevation curves down to the reference terminus elevation. For example, $\pm 2 \mathrm{~m}$ variations in the balance curves at the reference terminus (corresponding to observed variability in annual values for the extrapolated $b_{\mathrm{t}}^{\prime}$ ) typically changed the reference-surface average annual balance by $\pm 0.4 \mathrm{~m}$, less than one-tenth of the maximum variability in reference-surface average annual balances. 